\title{
AVALIAÇÃO DA INTERAÇÃO E DAS CONTRIBUIÇÕES DOS PRECEPTORES NA PERSPECTIVA DOS RESIDENTES DO PROGRAMA DE RESIDÊNCIA PEDAGÓGICA DA UFT - CAMPUS ARAGUAÍNA
}

Evaluation of the interaction and contributions of preceptors from the perspective of residents of the Pedagogical Residency Program of UFT - campus Araguaina.

Evaluación de la interacción y contribuciones de los preceptores desde la perspectiva de los residentes del Programa de Residencia Pedagógica de UFTcampus Araguaína.

\section{Jonierson de Araújo da Cruz ${ }^{* 1}$, Samuel Nepomuceno Ferreira ${ }^{1}$}

${ }^{1}$ Instituto Federal de Educação, Ciência e Tecnologia do Tocantins-Campus Araguaína, Araguaína, Brasil.

*Correspondência: Instituto Federal do Tocantins-Campus Araguaína, Av. Amazonas, esquina com Av.

Paraguai, Quadra 56, Lote 01, Araguaína, Tocantins, Brasil. CEP:77.824-838. e-mail

jonierson.cruz@ifto.edu.br.

\section{Artigo recebido em 28/02/2020 aprovado em 27/05/2020 publicado em 29/05/2020}

\section{INTRODUÇÃO}

Um importante momento curricular na formação de estudantes dos cursos de licenciatura é aquele onde deixam a cadeira universitária e desbravam o mundo escolar em suas múltiplas especificidades. No campo curricular esta ação é realizada por meio da disciplina de estágio supervisionado.

A prática em um contexto real escolar permite aos estudantes das licenciaturas conhecerem efetivamente os processos escolares de ensino e aprendizagem em seu amplo espectro, sejam eles no campo pedagógico ou administrativo (ROSA et al., 2018).

Não são recentes as discussões na esfera federal nacional sobre a implementação de programas de residência como propostas de política educacional (SILVA e CRUZ, 2018). As autoras nos apontam os diversificados momentos (e até mesmo diferentes nomenclaturas) em que estas discussões entram em voga no senado federal do Brasil, como, por exemplo, em 2007, quando se iniciaram as discussões sobre a residência educacional tendo a residência média como parâmetro comparativo (SILVA e CRUZ, 2018).

No ano de 2018 a Capes (Coordenação de Aperfeiçoamento de Pessoal de Nível Superior) lançou o primeiro edital do Programa de Residência Pedagógica. No programa são três os principais entes que sustentam a estrutura: o estudante de licenciatura (residente), um professor orientador da universidade vinculada e um professor (preceptor) da escola-campo.

$\mathrm{Na}$ estratégia de efetivação do programa os residentes estabelecem relações de troca de experiências diárias com os preceptores do programa. Neste sentido, o presente trabalho tem como principal objetivo trazer uma avaliação das relações estabelecidas entre residentes e preceptores 
no âmbito da execução da Residência Pedagógica da UFT, campus Araguaína.

\section{MATERIAIS E MÉTODOS}

Com a finalidade de obter as percepções dos residentes do programa, em uma abordagem qualitativa, foi construído um questionário contendo 7 (sete) perguntas, descritas na tabela 1 abaixo, e aplicado por meio da plataforma virtual google formulários.

O questionário foi respondido, de forma anônima, por 19 (dezenove) estudantes/residentes da UFT - campus Araguaína dos subprojetos de Química, Física, Matemática, Biologia e História.

Tabela 1: Perguntas avaliadas no questionário respondido pelos discentes residentes.

\begin{tabular}{|c|c|}
\hline $\begin{array}{c}\text { Pergunta } \\
1\end{array}$ & $\begin{array}{l}\text { Em uma escala de } 1 \text { a } 5 \text {, qual número } \\
\text { representaria o grau de INTERAÇÃO entre } \\
\text { você, residente, e seu preceptor? }\end{array}$ \\
\hline $\begin{array}{c}\text { Pergunta } \\
2\end{array}$ & $\begin{array}{l}\text { Seu preceptor realizava reuniões de } \\
\text { instrução/orientação? Qual era a } \\
\text { frequência? }\end{array}$ \\
\hline $\begin{array}{c}\text { Pergunta } \\
3\end{array}$ & $\begin{array}{l}\text { A elaboração e execução do cronograma de } \\
\text { trabalho foi adequada e cumprida ao tempo } \\
\text { de execução do programa? }\end{array}$ \\
\hline $\begin{array}{c}\text { Pergunta } \\
4\end{array}$ & $\begin{array}{l}\text { Sobre a etapa de AMBIENTAÇÃO na } \\
\text { escola-campo, quais ações foram } \\
\text { executadas por seu preceptor que } \\
\text { contribuíram para que você conhecesse os } \\
\text { espaços e as interações escolares? }\end{array}$ \\
\hline $\begin{array}{c}\text { Pergunta } \\
5\end{array}$ & $\begin{array}{l}\text { Sobre a etapa de IMERSÃO, quais ações } \\
\text { foram executadas por seu preceptor que } \\
\text { contribuíram para que você tivesse } \\
\text { condições de assumir a regência da turma? }\end{array}$ \\
\hline $\begin{array}{c}\text { Pergunta } \\
6\end{array}$ & $\begin{array}{l}\text { Sobre a etapa de ELABORAÇÃO DO } \\
\text { RELATÓRIO FINAL, AVALIAÇÃO E } \\
\text { SOCIALIZAÇÃO DAS ATIVIDADES, } \\
\text { quais ações foram executadas por seu } \\
\text { preceptor que contribuíram para que você } \\
\text { executasse e concluísse esta etapa? }\end{array}$ \\
\hline $\begin{array}{c}\text { Pergunta } \\
7\end{array}$ & $\begin{array}{l}\text { Acerca de todo o processo, cite pontos } \\
\text { FAVORÁVEIS e DESFAVORÁVEIS } \\
\text { sobre as contribuições de seu preceptor. }\end{array}$ \\
\hline
\end{tabular}

\section{RESULTADOS E DISCUSSÃO}

Para a pergunta 1, dezessete residentes classificaram entre 4 e 5 a interação entre os residentes e preceptores, de modo que os outros dois estudantes definiriam para esta questão o valor médio da escala, que variava entre 1 e 5 . Deste modo, a interação dos residentes com os preceptores pode ser vista como um agente facilitador para o desenvolvimento das ações do programa, visto que o contato entre estes entes se deu ao longo de todo o processo e em todas as etapas de execução.

Muitas atribuições dos preceptores exigiam momento de reunião para organização das tarefas e ações a serem elaboradas e aplicadas. Deste modo, com a pergunta 2, constatamos que os preceptores realizaram reuniões com os residentes com frequência semanal (seis residentes), mensal (sete residentes) e esporadicamente (seis residentes). Uma das opções de resposta do questionário, que não foi relatada por nenhum residente, versava sobre "não tive reuniões de instrução/orientação".

Buscando compreender a organização temporal para a elaboração e execução das ações do programa na relação residente-preceptor, constatamos, com a questão 3, que para uma grande parcela dos residentes foi possível adequar as ações ao tempo do programa, uma vez que treze estudantes elaboraram e executaram suas ações integralmente.

Para a organização das ações do programa a estrutura de execução nas escolas-campo foi dividida em três etapas: ambientação, imersão e a finalização com a elaboração do relatório final e a socialização das atividades desenvolvidas. Sendo assim, as questões 4, 5 e 6 analisaram quais ações os preceptores executaram em cada uma das três etapas.

Para a ambientação, na questão 4, os relatos nos sugerem que houve um bom espaço nas ações para que os residentes conhecessem a comunidade 
escolar e os espaços físicos do local onde residiriam. Alguns relatos seguem abaixo:

Aluno A: "Antes das aulas começarem nosso preceptor marcou uma reunião e nos apresentou a escola, as salas, laboratório, biblioteca, foi muito importante nesse processo de ambientação.";

Aluno B: "Apresentação da estrutura, corpo docente e demais representantes da unidade escolar, apresentando também atividades e projetos que iriam ser feitos.".

Quanto imersão (pergunta 5), momento em que os residentes de fato eram regentes em sala de aula, é perceptível as ações de orientação aos residentes por parte dos preceptores, desde "[...] informando dificuldade e problema." e "[...] dava uma sugestão no conteúdo, ou alguma dica para o controle da turma [...]" até mesmo realizando "[...] pequenas intervenções durante sua aula [...]".

Para a última etapa, sendo ela a elaboração do relatório final, avaliação e socialização das atividades, pelos relatos dos residentes, houve diferentes formas de participação dos preceptores. Alguns dos preceptores não participaram efetivamente da última etapa entendendo que esta seria de modo individual para cada ente do processo. Entretanto, muitos deram sugestões de melhorias no relatório final do residente, realizaram reuniões para avaliação do processo e um relato sobre auxilio na elaboração do trabalho apresentado no seminário final da residência.

Como última pergunta do questionário (pergunta 7), os residentes destacaram pontos favoráveis e desfavoráveis, tendo um olhar sobre todo o programa. Uma grande parcela dos residentes levantou como pontos favoráveis o apoio dado tanto na regência do próprio residente quanto, em um aspecto macro, nos ensinamentos sobre a vivência na instituição escolar. Um relato interessante demostrou, como ponto favorável, a organização dos preceptores do mesmo subprojeto ao trabalharem em um sistema de rodízio onde todos os residentes puderam conhecer todas as escolas-campo daquele subprojeto. Como pontos desfavoráveis, algumas ponderações como a não disponibilidade dos preceptores em alguns momentos por terem outras responsabilidades e também a necessidade de melhorar o contato com os residentes para que não ocorressem desencontros.

\section{CONCLUSÃO}

Apesar de ter sido implementado pela primeira vez e que tornou o programa inovador para os três entes, as relações estabelecidas, em especial, entre os discentes residentes e os preceptores das escolas-campo, são necessárias para o êxito das ações em todas as três etapas do programa.

Ao se dispor a acompanhar o residente na elaboração dos planos de atividades, na execução das ações de regência e no feedback avaliativo do residente o preceptor assume o papel de mediador do processo de aproximação dos conhecimentos conceituais e pedagógicos apropriados na universidade com os conhecimentos e habilidades necessárias para uma boa prática docente, reafirmando o principal objetivo do programa de Residência Pedagógica: promover a articulação entre a teoria e a prática no processo de aprendizagem dos cursos de licenciatura.

\section{AGRADECIMENTO}

Agradecemos aos residentes que desprenderam tempo para responder ao questionário, à UFT por abraçar o projeto e a Capes pela iniciativa do programa em âmbito nacional. 
Todos os autores declararam não haver qualquer potencial conflito de interesses referente a este artigo.

\section{REFERÊNCIAS}

ROSA, T. M. O.; SILVA, L. H. O. DA; SILVA, E. DA. Experiências de estágio supervisionado num curso de licenciatura em letras: sentidos e interações nos espaços de formação. Revista Observatório, v. 4, n. 5, p. 487-511, 1 ago. 2018.

SILVA, K. A. P. C; CRUZ, S. P. S. A Residência Pedagógica na formação de professores: história, hegemonia e resistências. Revista Momento: diálogos em Educação, v. 27, p. 227, 2018. 